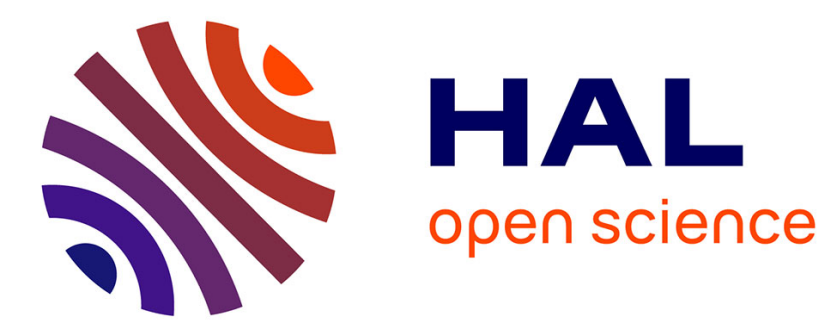

\title{
PET Imaging in Glioblastoma: Use in Clinical Practice
}

\author{
Antoine Verger, Karl-Josef Langen
}

\section{To cite this version:}

Antoine Verger, Karl-Josef Langen. PET Imaging in Glioblastoma: Use in Clinical Practice. Glioblastoma, Codon Publications, pp.155-174, 2017, 10.15586/codon.glioblastoma.2017.ch9 . hal-03268418

\section{HAL Id: hal-03268418 \\ https://hal.univ-lorraine.fr/hal-03268418}

Submitted on 23 Jun 2021

HAL is a multi-disciplinary open access archive for the deposit and dissemination of scientific research documents, whether they are published or not. The documents may come from teaching and research institutions in France or abroad, or from public or private research centers.
L'archive ouverte pluridisciplinaire HAL, est destinée au dépôt et à la diffusion de documents scientifiques de niveau recherche, publiés ou non, émanant des établissements d'enseignement et de recherche français ou étrangers, des laboratoires publics ou privés.

\section{(ㄷ)(1) $\$$}

Distributed under a Creative Commons Attribution - NonCommercial| 4.0 International 


\title{
PET Imaging in Glioblastoma: Use in Clinical Practice
}

\author{
ANTOINE VERGER ${ }^{1,2} \bullet$ KARL-JOSEF LANGEN $^{3,4}$
}

${ }^{1}$ Department of Nuclear Medicine \& Nancyclotep Imaging Platform, CHRU Nancy, Lorraine University, France; ${ }^{2}$ IADI, INSERM, UMR 947, Lorraine University, Nancy, France; ${ }^{3}$ Department of Nuclear Medicine, University of Aachen, Aachen, Germany; ${ }^{4}$ Institute of Neuroscience and Medicine, Forschungszentrum Jülich, Jülich, Germany

Author for correspondence: Antoine Verger, Service de Médecine Nucléaire, Hôpital de Brabois, 54500 Vandoeuvre les Nancy, France.

Email: a.verger@chru-nancy.fr

Doi: http://dx.doi.org/10.15586/codon.glioblastoma.2017.ch9

\begin{abstract}
Positron emission tomography (PET) is a nuclear medicine imaging method with increasing relevance for the diagnosis, prognostication, and monitoring of glioblastomas. PET provides additional insight beyond magnetic resonance imaging (MRI) into the biology of gliomas, which can be used for noninvasive grading, differential diagnosis, delineation of tumor extent, planning of surgery, and radiotherapy and post-treatment monitoring. In clinical practice, two classes of radiotracers have been used predominantly for imaging purposes, namely glucose metabolism tracers and amino acid transport tracers. Both classes of tracers can provide information on grading and prognosis of gliomas, but amino acid tracers, which exhibit lower uptake in normal brain tissue, are better suited for delineation of tumor extent, treatment planning, or follow-up than ${ }^{18} \mathrm{~F}$-2-fluoro2-deoxy-D-glucose $\left({ }^{18} \mathrm{~F}\right.$-FDG). Owing to the progress in PET imaging using radiolabeled amino acids in recent years, the Response Assessment in Neuro-Oncology (RANO) working group, an international effort to develop new standardized response criteria for clinical trials in brain tumors, has recently recommended amino acid PET as an additional tool in the diagnostic assessment of brain tumors.
\end{abstract}

In: Glioblastoma. Steven De Vleeschouwer (Editor), Codon Publications, Brisbane, Australia ISBN: 978-0-9944381-2-6; Doi: http://dx.doi.org/10.15586/codon.glioblastoma.2017

Copyright: The Authors.

Licence: This open access article is licenced under Creative Commons Attribution 4.0 International (CC BY 4.0). https://creativecommons.org/licenses/by-nc/4.0/ 
These developments as well as multimodality imaging should improve the diagnostic assessment of these tumors.

Keywords: ${ }^{11} \mathrm{C}-\mathrm{MET}$ PET; ${ }^{18} \mathrm{~F}-\mathrm{FDG}$ PET; ${ }^{18} \mathrm{~F}-\mathrm{FD}$-po PET; ${ }^{18} \mathrm{~F}-\mathrm{FET}$ PET; Glioblastoma

\section{Introduction}

The incidence of primary malignant brain and central nervous system tumors in the general population was estimated at 3 per 100,000 in 2008, with a higher incidence rate in developed countries than in developing countries (1). Among these tumors, glioblastomas account for approximately $60-70 \%$ of malignant gliomas $(2,3)$. With maximum safe resection, radiotherapy, and concurrent and adjuvant temozolomide, in clinical trial populations, the medium survival is 12-15 months (4-7). Unfortunately, after initial treatment, these tumors invariably recur. Initial diagnosis, prognosis, and targeted treatment of these tumors thus represent very active areas of investigation.

In this setting, neuroimaging plays a key role in the assessment of these tumors (8). Magnetic resonance imaging (MRI), the current imaging gold standard, has offered limited insight to date with regard to grade of malignancy, tumor delineation, differentiation between necrotic tissues and recurrent tumor, as well as the management of therapeutic interventions such as surgery or radiotherapy $(9,10)$. In fact, although a rapidly enlarging or enhancing lesion on MRI with or without clinical symptoms is usually considered a progressing tumor, imaging the extent of contrast enhancement in malignant gliomas has limited accuracy due to the difficulty in distinguishing between progressive tumor and treatment-induced changes such as radiation necrosis (11).

Positron emission tomography (PET) is a nuclear medicine method with an increasing relevance especially due to the improved availability of radioactively labeled amino acids, allowing widespread applications in diagnosis, therapy planning, and therapy monitoring of glioblastomas $(9,10)$. PET provides additional insight beyond MRI into the biology of gliomas which can be used for noninvasive grading, differential diagnosis, delineation of tumor extent, planning of surgery and radiotherapy, post-treatment monitoring, and prognostication. Among PET radiotracers, ${ }^{18} \mathrm{~F}$-2-fluoro-2-deoxy-D-glucose $\left({ }^{18} \mathrm{~F}-\mathrm{FDG}\right)$ is the most widely studied and validated tracer to date. In addition, ${ }^{18} \mathrm{~F}-\mathrm{FDG}$ is widespread in clinical nuclear medicine and is of low cost (8). In instances of suspicious low-grade glioma, it is able to identify anaplastic transformation and displays good prognostic value. Indeed, tumor cells are characterized by increased glycolytic metabolism, in parallel with cell proliferation and loss of differentiation. ${ }^{18} \mathrm{~F}-\mathrm{FDG}$ is an appropriate, albeit nonspecific radiotracer for noninvasively assessing the biological aggressiveness of tumors in vivo, as previously suggested in many cancer types (12). However, a high ${ }^{18} \mathrm{~F}-\mathrm{FDG}$ uptake in surrounding normal brain tissue limits its use for the imaging of cerebral gliomas which may not be visualized in a large fraction of primary and recurrent tumors (13).

Due to the relatively low tracer uptake in normal gray matter, amino acid PET tracers can detect gliomas with greater sensitivity than ${ }^{18} \mathrm{~F}-\mathrm{FDG}$ in primary 
and recurrent tumors and are helpful in differentiating recurrent tumors from treatment-induced changes $(14) .{ }^{11} \mathrm{C}$-methyl-methionine $\left({ }^{11} \mathrm{C}\right.$-MET) is the most studied and validated amino acid tracer. It is a natural amino acid avidly taken up by glioma cells, with only a low uptake in normal cerebral tissue. A smaller portion of ${ }^{11} \mathrm{C}$-MET is metabolized by decarboxylation. However, several experiments have suggested that during PET studies, tumor uptake of ${ }^{11} \mathrm{C}$-MET mainly reflects increased amino acid transport (15). Its major drawback lies in the short half-life of the ${ }^{11} \mathrm{C}$-carbon, only $20 \mathrm{~min}$, and thus requires close proximity to a cyclotron, thereby limiting its use in routine nuclear medicine centers. To overcome the drawbacks of the short-lived MET, ${ }^{18} \mathrm{~F}$-labeled amino acids have been developed in order to expand amino acid tracer utilization, namely O-(2-[18F]-fluoroethyl)-L-tyrosine $\left({ }^{18} \mathrm{~F}-\mathrm{FET}\right)$ and 3,4-dihydroxy6 -[18F]-fluoro-L-phenylalanine ( $\left.{ }^{18} \mathrm{~F}-\mathrm{FDOPA}\right) .{ }^{18} \mathrm{~F}-\mathrm{FET}$ is increasingly used in Europe as a tracer for both high-grade gliomas as well as low-grade gliomas, owing to its several advantages including synthesis by an efficient nucleophilic reaction, elevated uptake by tumor tissues, low uptake by inflammatory tissues, and high stability (16). Similar to ${ }^{11} \mathrm{C}$-MET and ${ }^{18} \mathrm{~F}-\mathrm{FET},{ }^{18} \mathrm{~F}-\mathrm{FDOPA}$ is incorporated into cells through amino acid transporters that are overexpressed in gliomas, and its transport and uptake are independent of the blood-brain barrier (17). Of note, a striatal uptake has nonetheless been reported in the case of ${ }^{18} \mathrm{~F}-\mathrm{FDOPA}$, which may lead to difficulties in delineating gliomas in these areas (17).

The aim of this chapter is to define clinical practice PET indications in glioblastomas for the purposes of diagnosis, delineation of glioma extent, as well as its value in treatment planning, follow-up, and prognostication. The following mainly focuses on imaging tracers of glucose metabolism $\left({ }^{18} \mathrm{~F}-\mathrm{FDG}\right)$ and amino acid transport $\left({ }^{11} \mathrm{C}\right.$-MET, ${ }^{18} \mathrm{~F}$-FET, and ${ }^{18} \mathrm{~F}$-FDOPA), since these compounds are already part of current clinical practice. Future perspectives in novel radiotracers and technical improvements are also outlined.

\section{Primary Diagnosis/Differential Diagnosis}

${ }^{18} \mathrm{~F}-\mathrm{FDG}$ is useful for differentiating high-grade gliomas from other types of brain tumors (18). In the specific setting of glioblastomas, ${ }^{18} \mathrm{~F}-\mathrm{FDG}$ is particularly sensitive at the initial stage of the diagnosis $(19,20)$, an example of which is given in Figure 1. In a study involving 31 newly diagnosed glioblastomas, Colavolpe et al. found an uptake of ${ }^{18} \mathrm{~F}-\mathrm{FDG}$ in these tumors with a tumor-to-background ratio $\max$ (TBRmax) of $1.4 \pm 0.8$ (12). However, differential diagnosis at the initial stage with ${ }^{18} \mathrm{~F}$-FDG may be difficult to achieve due to the low specificity of this radiotracer. Indeed, brain lymphomas can display a higher glucose metabolism uptake than high-grade gliomas (21). Moreover, nonneoplastic neurological diseases can mimic brain neoplasms on ${ }^{18} \mathrm{~F}-\mathrm{FDG}$, including pyogenic abscesses, tuberculosis, fungal infections, or sarcoidosis (22). Studies comparing the ${ }^{18} \mathrm{~F}-\mathrm{FDG}$ and amino acid tracer uptake in the assessment of brain tumors demonstrated significantly higher tumor to brain contrast with amino acid PET than with ${ }^{18} \mathrm{~F}-\mathrm{FDG}$ (23-25), demonstrating a higher sensitivity of amino acid tracers for glioblastoma detection. 


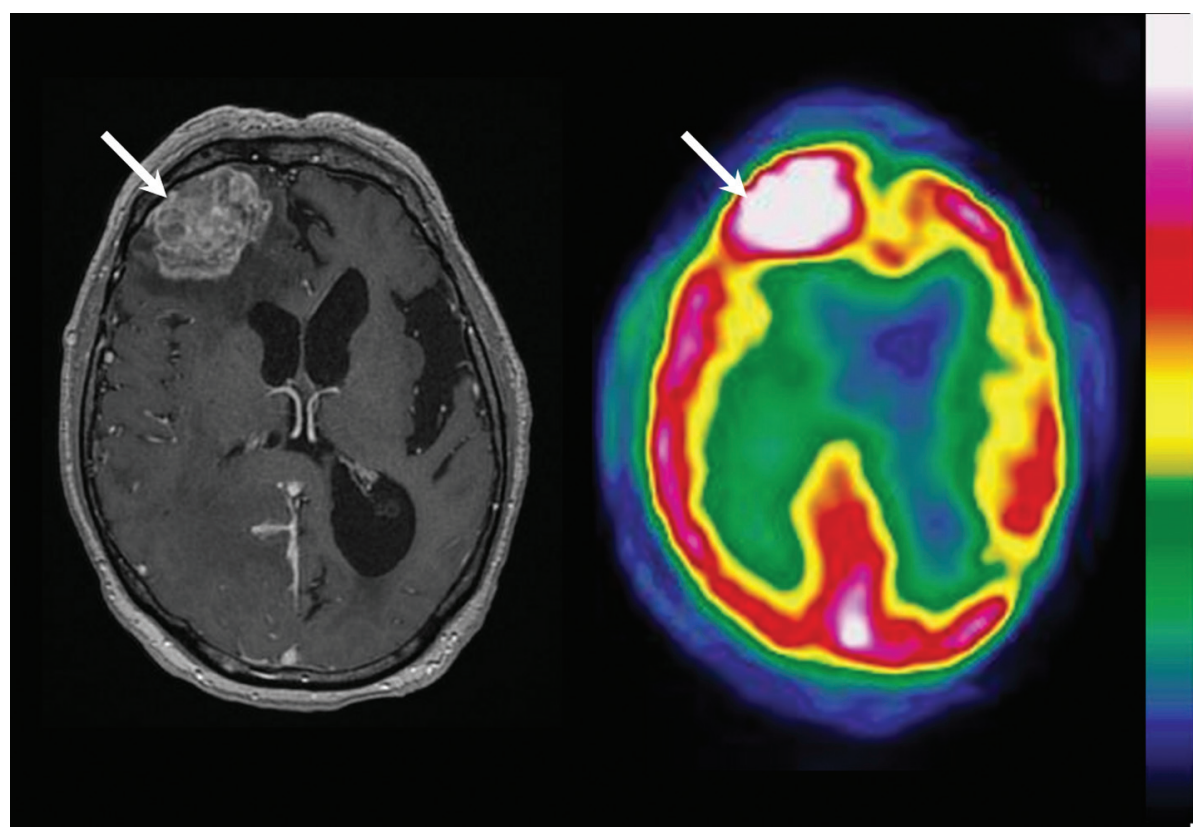

Figure 1 Primary diagnosis of a right frontal glioblastoma in a 79-year-old man following acquisition of axial slices of T1-weighted gadolinium-enhanced MRI (left side) and ${ }^{18} \mathrm{~F}$-FDG PET (right side). The right frontal glioblastoma is contrast-enhanced on MRI (white arrow) and shows an extensive uptake of ${ }^{18} \mathrm{~F}$-FDG PET (white arrow), despite the high uptake in surrounding normal brain tissue.

${ }^{18} \mathrm{~F}$-FET has shown comparable results to ${ }^{11} \mathrm{C}-\mathrm{MET}$ in the detection of brain gliomas (26). Approximately $95 \%$ of high-grade gliomas, including glioblastomas, display a significant uptake of ${ }^{18}$ F-FET (27-29), leading to a high sensitivity of ${ }^{18} \mathrm{~F}$-FET for tumor detection. A study conducted in rats demonstrated that ${ }^{18} \mathrm{~F}$-FET uptake was absent in macrophages, a common inflammatory mediator, in contrast to accumulation of ${ }^{18} \mathrm{~F}$-FDG in these cells (30). Nevertheless, in patient studies, unspecific FET uptake has been observed in nonneoplastic brain lesions $(28,31)$. Despite its limited specificity $(32),{ }^{18} \mathrm{~F}-\mathrm{FDOPA}$ is also a sensitive tool for diagnosing glioblastomas with similar results to ${ }^{11} \mathrm{C}-\mathrm{MET}$ (33). For instance, in a study of 23 histologically confirmed tumors, ${ }^{18}$ F-FDOPA had a TBRmax of $2.50 \pm$ 0.73 for 18 high-grade tumors, 3 of which were glioblastomas (24).

In the diagnosis of gliomas, noninvasive tumor grading may be helpful in order to define aggressive forms at initial stages with poor prognosis. In this instance, ${ }^{18} \mathrm{~F}-\mathrm{FDG}$ is helpful to detect glioblastomas, since low-grade gliomas often appear as hypometabolic lesions, particularly when compared with cortical uptake (34). However, due to its high uptake in gray matter, tumor to brain ratios of ${ }^{18} \mathrm{~F}-\mathrm{FDG}$ uptake are low $(1.23 \pm 0.69)$ for high-grade tumors, leading to a poorer tumor imaging contrast in comparison to amino acid tracers (24). ${ }^{18}$ F-FDOPA uptake was found to be significantly higher in high-grade tumors compared to low-grade tumors in newly diagnosed but nonrecurrent tumors that 
had been previously treated in a series of 59 gliomas of which 25 were glioblastomas (35). In another study, ${ }^{18} \mathrm{~F}$-FDOPA uptake was significantly different in highgrade and low-grade gliomas or for both newly diagnosed and recurrent gliomas in a series of 31 gliomas of which 5 were glioblastomas (17). Similarly, several studies, including those on glioblastomas, have shown significantly different TBRmax between high-grade and low-grade gliomas with ${ }^{11} \mathrm{C}-\mathrm{MET}$ (36-38), although other study results are more controversial $(39,40)$.

For ${ }^{18} \mathrm{~F}-\mathrm{FET}$, it has been shown that a TBRmax $<2.5$ excludes a high-grade tumor with high probability (27). Furthermore, ${ }^{18}$ F-FET accuracy for tumor grading can be markedly improved by assessing dynamic PET data, which typically show steadily increasing time-activity curves in low-grade gliomas, as opposed to an early activity peak around $10-20 \mathrm{~min}$ after injection, followed by decreased uptake in high-grade gliomas $(41,42)$. Accordingly, in a study combining MRI and dynamic ${ }^{18}$ F-FET data for initial glioma grading (43), the authors concluded that on multivariate logistic regression analysis, a negative slope of the tumor FET time-activity curve remains the best predictor of highgrade glioma. Analysis of dynamic data was not helpful for tumor grading neither with ${ }^{11} \mathrm{C}$-MET $(44)$ nor with ${ }^{18} \mathrm{~F}$-FDOPA $(45,46)$. Altogether, PET is helpful in the diagnostic evaluation of glioblastomas at the initial stage by means of glycolytic or amino acid metabolism-based tracers. Differential diagnosis with nonneoplastic lesions, however, is poorer with ${ }^{18} \mathrm{~F}-\mathrm{FDG}$ due to its low specificity. On the contrary, all commonly used PET tracers can contribute to the differentiation of glioblastomas from low-grade gliomas, especially ${ }^{18} \mathrm{~F}-\mathrm{FET}$, when using dynamic data.

\section{Delineation of Glioma Extent}

The accurate definition of initial tumor volume as well as extent of recurrence is essential in treatment planning. Accordingly, PET data provide valuable additional information compared with MRI, which suffers from high interindividual variability in delineation of glioblastoma target volumes (47). Furthermore, multiple histopathological and postmortem series have demonstrated the limitations of conventional MRI in defining the extent of gliomas $(48,49)$. Amino acid PET tracers are the better candidates for this indication compared with ${ }^{18} \mathrm{~F}-\mathrm{FDG}$, which exhibits high uptake in normal brain tissue (13). In a study involving 12 patients with recurrent glioblastoma, the metabolically active tumor volume as defined by ${ }^{11} \mathrm{C}$-MET PET was substantially underestimated by contrast enhancement in MRI. These findings support the notion that information derived from ${ }^{11} \mathrm{C}$-MET uptake in addition to contrast-enhanced MRI may be helpful in optimized targeting of the tumor mass by surgery and radiotherapy (50).

Similarly, some studies in which the radiological findings were compared with the histological findings in tissue samples obtained by biopsy or open surgery have provided evidence that FET PET detects the solid mass of gliomas and metabolically active tumor areas more reliably than MRI $(51,52)$. Furthermore, in a study of initial diagnosis of 56 gliomas, 24 of which were glioblastomas, ${ }^{18} \mathrm{~F}-\mathrm{FET}$ showed considerably higher TBRmax and larger tumor volumes when compared to regional cerebral blood volume maps derived from perfusion-weighted 
MR imaging (53). In addition, postoperative ${ }^{18}$ F-FET PET has been shown to reveal residual tumor with higher sensitivity than MRI as well as show larger tumor volumes (54). In this latter series of 62 patients with recurrent glioblastoma, ${ }^{18} \mathrm{~F}$-FET was thus recommended as a helpful adjunct in addition to MRI for postoperative assessment of residual tumor (54). Similar results have been obtained with ${ }^{18} \mathrm{~F}$-FDOPA PET in progressive or recurrent glioblastomas where a larger tumor extent was identified when compared with MRI-derived regional cerebral blood volume maps (55). Accordingly, ${ }^{18}$ F-FDOPA PET-based tumor volumes have been shown to extend beyond the contrast-enhancing volume on conventional MRI (56). In addition, initial nonenhancing glioblastoma areas were also identified with this radiotracer since they were subsequently followed by abnormal MRI contrast enhancement (57).

\section{Value in Treatment Planning BIOPSY AND RESECTION}

PET enables better identification of intra-tumor heterogeneity compared with standard MRI in addition to delineating tumor extent with much greater accuracy. The identification of malignant foci, commonly defined as "hot spots" in heterogeneous gliomas and a specific characteristic of glioblastomas (58), is essential for biopsy planning. The objective is to ensure that the most biologically aggressive portion of the tumor, which ultimately determines the patient's prognosis as well as treatment, is not under-sampled (56, 59). Similar to the delineation of tumor extent, amino acid tracers are more suitable than ${ }^{18}$ F-FDG in identifying malignant foci in gliomas. In a study aimed at guiding stereotactic brain biopsy of gliomas by using ${ }^{18} \mathrm{~F}-\mathrm{FDG}$ and ${ }^{11} \mathrm{C}-\mathrm{MET}$, the authors showed that all 32 gliomas, 10 of which were glioblastomas, exhibited an area of abnormal ${ }^{11} \mathrm{C}$-MET uptake, whereas only 7 glioblastomas showed abnormal ${ }^{18} \mathrm{~F}-\mathrm{FDG}$ uptake (60). An example of superiority of ${ }^{11} \mathrm{C}$-MET in comparison to ${ }^{18} \mathrm{~F}-\mathrm{FDG}$ is given in Figure 2. In another study aimed at comparing performances with MRI, stereotactic PET-guided biopsies were also performed with ${ }^{18} \mathrm{~F}$-FDOPA PET. Thirteen of the 16 high-grade biopsy specimens were obtained from regions of elevated ${ }^{18} \mathrm{~F}-\mathrm{FDOPA}$ uptake, while MRI contrast enhancement was present in only 6 of the aforementioned 16 samples (56). These observations, in accordance with previous results, thus underscore the potential benefit of using PET amino acid tracers in determining the most aggressive portion of the tumor.

Of particular interest, in a study using a combination of ${ }^{18} \mathrm{~F}-\mathrm{FDG}$ and ${ }^{11} \mathrm{C}-\mathrm{MET}$, surgical tumor resection based on PET tracer uptake was found to be significantly associated with longer survival in glioblastoma patients when compared with surgical resection based on MRI contrast enhancement (61). Thus, in addition to its value in biopsy planning, PET data provide added prognostic value with regard to surgical resection outcome (61). It has moreover been suggested that patients with glioblastomas may potentially benefit from maximal PET-guided tumor resection since lower biological tumor volume (BTV) before treatment with ${ }^{18}$ F-FET was independent of clinical prognostic factors: patients with smaller tumor volumes had significantly longer progression-free and overall survival (62). 

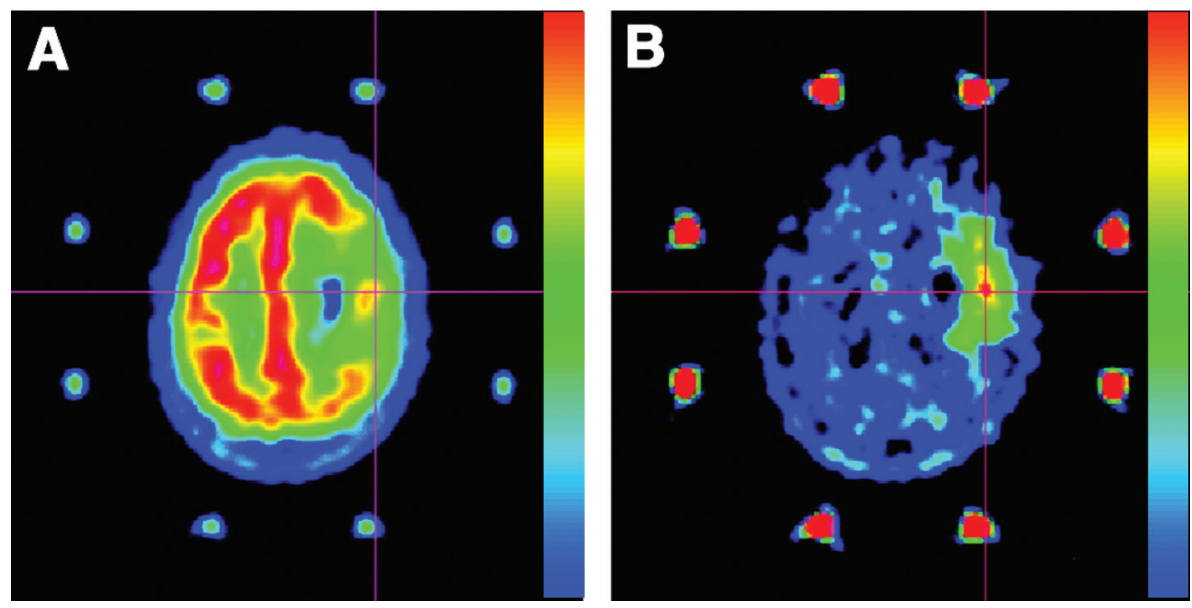

Figure 2 PET performed with ${ }^{18} \mathrm{~F}$-FDG (A) and 11C-MET (B) in a 62-year-old woman with a glioblastoma in the left prerolandic cortical area. Uptake of ${ }^{18} \mathrm{~F}-\mathrm{FDG}$ was reduced in the tumor area except for one area of uptake equivalent to that in the surrounding gray matter. Uptake of ${ }^{11} \mathrm{C}-\mathrm{MET}$ was higher in the tumor than in the surrounding cortex, allowing the definition of a target for biopsy. When PET images obtained with the two tracers were co-recorded, the highest focus of ${ }^{11} \mathrm{C}-\mathrm{MET}$ uptake corresponded to the hot spot of ${ }^{18} \mathrm{~F}-\mathrm{FDG}$ uptake (intersecting lines). (Adapted from J Nucl Med 2004;45:1293-1298. Copyright: The Society of Nuclear Medicine and Molecular Imaging, Inc. Reproduced with Permission.)

\section{RADIATION}

In radiotherapy treatment planning, ${ }^{18} \mathrm{~F}$-FDG PET can provide prognostic information. Indeed, ${ }^{18} \mathrm{~F}-\mathrm{FDG}$ PET volumes are predictive of survival and time to tumor progression in the treatment of patients with glioblastomas (63). However, ${ }^{18}$ F-FDG uptake abnormalities generally demonstrate a smaller region of uptake contained within the MRI abnormality, with only an occasional extension outside of the MRI target (63). ${ }^{18} \mathrm{~F}-\mathrm{FDG}$ PET is therefore of limited value for radiation treatment planning except for the definition of target volumes in radiation dose escalation. PET amino acid tracers are thus better suited to delineate tumor volume prior to radiotherapy. Accordingly, in a study of 39 patients with high-grade gliomas before radiotherapy, the region of ${ }^{11} \mathrm{C}$-MET uptake was larger and detected up to $45 \mathrm{~mm}$ beyond MRI contrast enhancement in 29 patients (15). Similarly, high-grade glioma contours obtained with ${ }^{18} \mathrm{~F}$-FDOPA PET-based consensus target volumes were larger than MRI-based volumes (64). ${ }^{11}$ C-MET PET was also found to provide supplementary information to MRI data, whereby BTV defined with ${ }^{11} \mathrm{C}$-MET PET included all localizations of recurrences in a series of 52 glioblastomas (65). Thus, these pretreatment ${ }^{11} \mathrm{C}$-MET PET volumes appear to identify areas at highest risk of recurrence for patients with glioblastomas since inadequate PET-gross-tumor-volume coverage was associated with increased risk of noncentral failures (66).

Of note, in re-irradiated patients, significant longer survival times have been reported using image fusion in treatment planning when compared with treated patients based on MRI/CT alone (67). Large BTC on ${ }^{18} \mathrm{~F}$-FET PET is accordingly 
an independent prognostic factor of poor overall survival and of progression-free survival in newly diagnosed glioblastoma patients, to the detriment of other prognosis factors such as clinical factors or MRI-based tumor volume $(62,68)$. A number of centers have accordingly begun to integrate amino acid imaging into CT-based and MRI-based radiotherapy planning (69), particularly in high-grade gliomas and in instances when high-precision radiotherapy is to be given, or in the setting of dose escalation studies, or for re-irradiation of recurrent tumors (70, 71). In this context, ${ }^{11} \mathrm{C}-\mathrm{MET} / \mathrm{CT} / \mathrm{MRI}$ fusion has also been proposed to optimize hypofractionated stereotactic radiotherapy by intensity-modulated radiation therapy (HS-IMRT) in recurrent glioblastomas, with good treatment tolerance and a median survival time of 11 months (72).

\section{Follow-up: Treatment Response, Progression, Pseudoprogression, and Radionecrosis}

The extent of MRI contrast enhancement is usually considered an indicator of treatment response or progression (73). However, contrast enhancement after radiotherapy with or without concomitant temozolomide can mimic tumor progression and is termed "pseudoprogression." This phenomenon typically occurs within the first 12 weeks after chemoradiation with concurrent temozolomide or radiotherapy alone $(74,75)$. Moreover, contrast enhancement is linked to nonspecific post-therapeutic effects, in the specific setting of post-radiation effects, occurring several months later than pseudoprogression (76). It is relatively similar to that observed in tumor recurrence thus impeding the differential diagnosis between radionecrosis and recurrence. Finally, since the introduction of antiangiogenic agents such as bevacizumab, the phenomenon of pseudoresponse further complicates the assessment of treatment response using standard MRI alone $(74,77)$.

${ }^{18}$ F-FDG PET shows a decreased metabolic rate of cerebral glucose after radiotherapy or chemotherapy even if hypermetabolism is observed in the early phase after radiotherapy mostly due to the inflammatory process $(20,78,79) .{ }^{18} \mathrm{~F}-\mathrm{FDG}$ nevertheless displays low specificity between radionecrosis and tumor recurrence (80) as well as a weak added value to MRI (81). In contrast, amino acid tracers appear to be better tools to provide sensitive monitoring of the response to various treatment options as well as the early detection of tumor recurrence, including an improved differentiation of tumor recurrence from post-therapeutic effects (82).

${ }^{11} \mathrm{C}$-MET is considered as very helpful in the assessment of these patients because the decrease in amino acid in the metabolically active tumor volume is a sign of treatment response associated with long-term outcome $(83,84)$. Accordingly, combined assessment with MRI and ${ }^{11} \mathrm{C}$-MET at 8 weeks can differentiate true responders, that is, those predicted to show a more favorable prognosis, from pseudoresponders (85). $\mathrm{F}^{18}$ labeled amino acid tracers can also determine treatment response after chemotherapy with a higher accuracy than MRI alone. A comparative illustration between ${ }^{18}$ F-FET PET and contrast-enhanced MRI is shown in Figure 3. For example, in a study involving 25 patients with glioblastoma after early completion of radiochemotherapy, a decrease in both ${ }^{18} \mathrm{~F}-\mathrm{FET}$ 

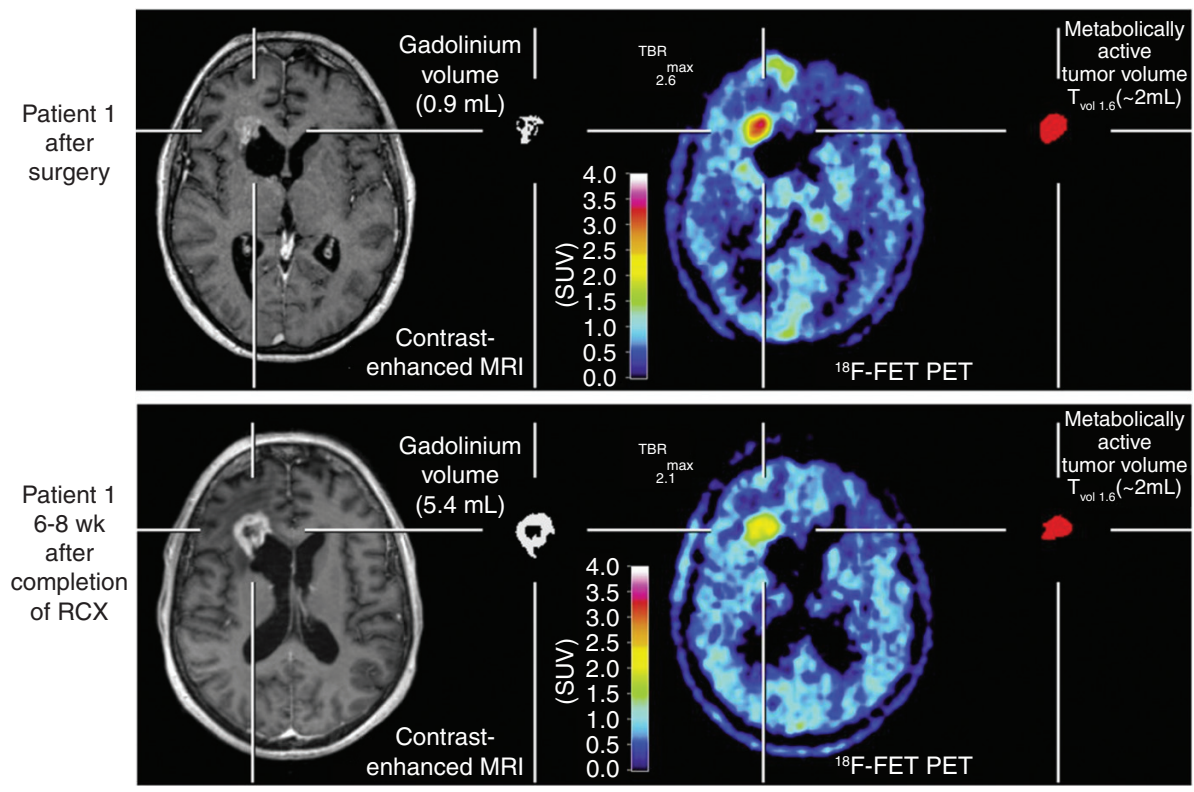

Figure $3{ }^{18}$ FET-PET in a 59-year-old woman with glioblastoma. Brain imaging was performed after surgery (upper panel; MRI-/FET-1) and 6-8 weeks after completion of radiochemotherapy (lower panel; MRI-/FET-3). Contrast-enhanced MRI with corresponding contrast-enhanced volume is shown on the left and ${ }^{18} \mathrm{~F}-\mathrm{FET}$ PET with corresponding metabolic volume on the right. Enlargement of contrast-enhanced volume on MRI 6-8 weeks after completion of radiochemotherapy (lower panel) is suggestive of tumor progression, whereas ${ }^{18}$ F-FET PET conversely indicates responsiveness with decreasing amino acid uptake (reduction of TBRmax) and unchanged metabolic volume. (Adapted from J Nucl Med 2012;53:1048-1057. Copyright: Society of Nuclear Medicine and Molecular Imaging, Inc. Reproduced with Permission.)

TBR(max) and TBR(mean) was found to be a highly significant and independent statistical predictor of progression-free survival and overall survival. On the contrary, contrast enhancement volume changes had no significant predictive value for survival (86).

Otherwise, it has been shown that ${ }^{18}$ F-FET PET is able to differentiate pseudoprogression from early tumor progression within the first 12 weeks after completion of radiochemotherapy with concomitant temozolomide. In patients with pseudoprogression, ${ }^{18}$ F-FET uptake was found to be significantly lower than in patients with early progression (TBRmax $1.9 \pm 0.4$ vs. $2.8 \pm 0.5$, TBRmean $1.8 \pm 0.2$ vs. $2.3 \pm 0.3$ ). Performances for diagnosis of pseudoprogression with ${ }^{18} \mathrm{~F}$-FET PET were high in sensitivity, specificity, and accuracy by using TBRmax reaching up to respectively, 100, 91, and 96\% (87). Moreover, a rapid increase in radiotracer uptake in time activity curves (shorter time to peak) was more frequently present in patients with tumor progression (87). Furthermore, a recent study has even proposed an original method of clustering based on textural ${ }^{18}$ F-FET PET features that could distinguish pseudoprogression from true tumor progression (88). In addition, ${ }^{18}$ F-FET PET has also been found to provide valuable information in assessing the elusive phenomenon of late pseudoprogression (89). 
${ }^{18} \mathrm{~F}$-FDOPA can identify treatment responders to antiangiogenic therapy as early as 2 weeks after treatment initiation and thus could be an efficient tool in case of suspicion of pseudoresponse (90). In a study involving antiangiogenic therapy, a decrease in ${ }^{18} \mathrm{~F}$-FDOPA PET tracer uptake was associated with longer progression-free survival and overall survival (91). Furthermore, in this latter study, the volume fraction of increased ${ }^{18}$ F-FDOPA PET uptake measured at two time points after bevacizumab treatment also enabled to stratify long-term and short-term progression-free survival as well as overall survival (91). Responders based on ${ }^{18}$ F-FDOPA PET data survived 3.5 times longer (12.1 months vs. 3.5 months of median overall survival) than nonresponders, which was much higher than responders based solely on MRI (90). Similar results have been reported for ${ }^{18}$ F-FET (92-94).

With regard to the differential diagnosis between tumor recurrence and radionecrosis, ${ }^{11} \mathrm{C}$-MET provides a better sensitivity and clearer delineation of the suspected recurrence (83). In a comparative study, ${ }^{11} \mathrm{C}$-MET was found to be superior to ${ }^{18} \mathrm{~F}-\mathrm{FDG}$ for diagnostic accuracy in distinguishing glioma recurrence from radiation necrosis (95). Similarly, in a prospective comparison with ${ }^{18}$ F-FDG PET, ${ }^{18} \mathrm{~F}-\mathrm{FDOPA}$ PET had a diagnostic accuracy of $100 \%$ for the diagnosis of glioblastoma recurrence versus $92.8 \%$ with ${ }^{18}$ F-FDG PET (96). In addition, in a study of 110 glioblastoma patients, ${ }^{18}$ F-FDOPA PET detected recurrence with high accuracy while lesion-to-normal-tissue ratios were predictive of progression-free survival (97). Finally, ${ }^{18} \mathrm{~F}$-FDOPA PET is also able to distinguish tumor recurrence from treatment-related changes (24), an example of which is depicted in Figure 4.

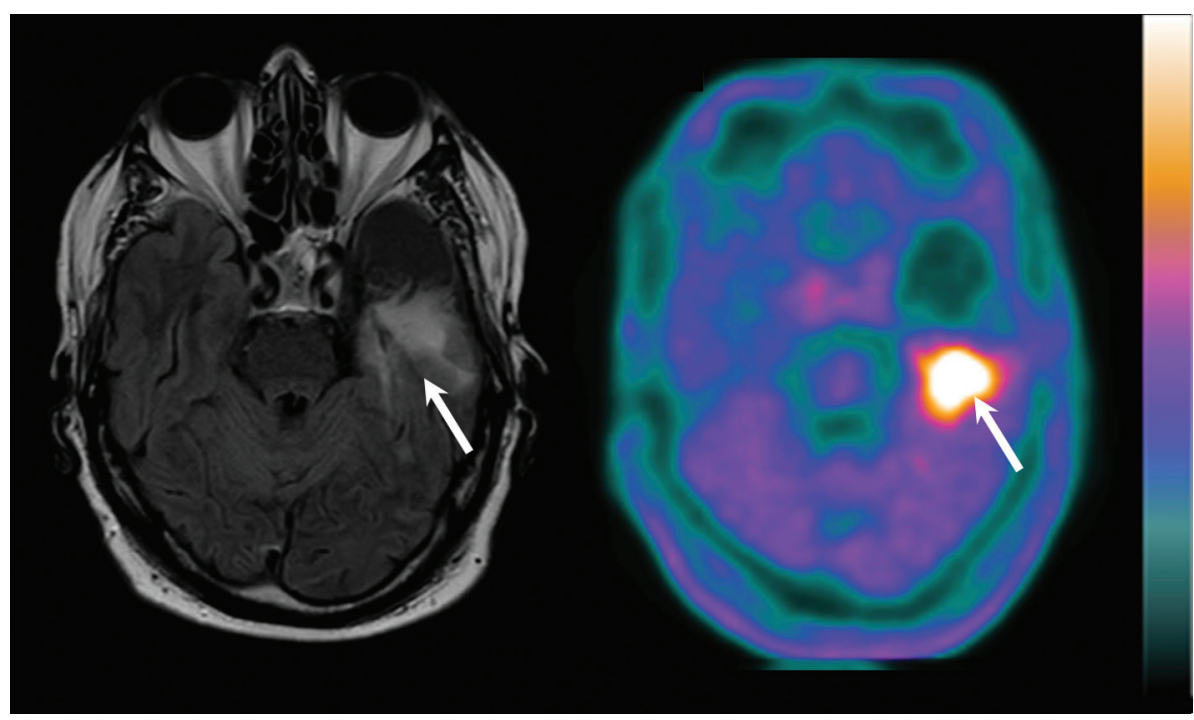

Figure 4 Left temporal glioblastoma recurrence in a 66-year-old man after surgery and adjuvant radiochemotherapy. The axial slice of Fluid-Attenuated Inversion Recovery (FLAIR)-weighted MRI (left side) shows a hypersignal at the posterior area of the exeresis cavity (white arrow), making the distinction between tumor recurrence and post-therapeutic effects somewhat challenging. The axial slice of ${ }^{18} \mathrm{~F}$-FDOPA PET shows an intense uptake in the same area (white arrow), which is strongly in favor of tumor recurrence. 
In a similar manner, static and dynamic ${ }^{18} \mathrm{~F}-\mathrm{FET}$ PET parameters can differentiate progressive or recurrent glioma from treatment-related nonneoplastic changes with a higher accuracy than conventional MRI, especially with regard to glioblastoma recurrence $(98,99)$.

\section{Prognostication}

${ }^{18}$ F-FDG provides an additional prognostic value to MRI (100) in newly diagnosed (12) or recurrent glioblastomas (101). Indeed, the tumor-to-normal brain tissue ratio has been reported to predict overall survival in a newly diagnosed glioblastoma subgroup, independently of age, Karnofsky performance status, histological grade, and surgery (12). In addition, in a series of 20 recurrent glioblastomas, ${ }^{18} \mathrm{~F}-\mathrm{FDG}$ uptake was found to be the most powerful predictor of both progression-free survival and overall survival, using either univariate or multivariate analysis, among all variables tested, including histological grade, Karnofsky performance status, steroid intake, and number of previous treatments (101).

Prognostic value is also a feature of amino acid tracers. Indeed, ${ }^{11} \mathrm{C}-\mathrm{MET}$ uptake is correlated to prognostic, histological, and molecular parameters in gliomas at initial stage (102). Moreover, a prospective multicenter trial investigating the role of pretreatment ${ }^{18} \mathrm{~F}-\mathrm{FET}$ PET in newly diagnosed glioblastoma found BTV prior to radiochemotherapy to be highly prognostic of outcome (62). Furthermore, ${ }^{18}$ F-FET PET time-activity curves before treatment and their changes after radiochemotherapy were also related to outcome, whereby patients with increasing time-activity curves experienced longer overall survival (62). This latter observation is in accordance with results of previous studies investigating amino acid PET in malignant glioma prior to therapy in which volumetry of ${ }^{11} \mathrm{C}$-MET uptake was a pretreatment prognostic marker in patients with malignant glioma (103). Interestingly, tumor-to-normal brain tissue ratio using ${ }^{18}$ F-FDOPA PET was also reported as an independent predictor of survival, along with the size of recurrent tumor on MRI in patients with suspected recurrent glioblastomas (104). More recently, a combination of two radiotracers was used to define a metabolic tumor volume in hypoxia, with the latter expressed as the volume of ${ }^{18} \mathrm{~F}$-FDG $/{ }^{18} \mathrm{~F}$-fluoromisonidazole ( ${ }^{18} \mathrm{~F}$-FMISO) double-positive, and ${ }^{18} \mathrm{~F}$-FMISO used as a radiotracer of hypoxia. This metabolic tumor volume in hypoxia was a significant predictor of progression-free survival and overall survival in glioblastoma patients (105).

\section{Future Perspectives: Novel Radiotracers and Multimodality}

Several other radiotracers have been developed for diagnosis, prognosis, or follow-up of glioblastomas (106). Among the better-known compounds, the aforementioned ${ }^{18} \mathrm{~F}$-FMISO, a nitroimidazole derivative, was developed as a PET imaging agent of hypoxia (107), through the trapping of its metabolites into hypoxic cells (108). Hypoxia in tumors is a pathophysiological consequence of 
structurally and functionally disturbed angiogenesis along with a deterioration in the ability of oxygen to diffuse through the tissues and is associated with progression and resistance to radiotherapy (109). ${ }^{18} \mathrm{~F}$-FMISO uptake has been found in high-grade gliomas, but not in low-grade gliomas, along with a significant relationship between its uptake and expression of the angiogenesis marker VEGF-R1. Thus, ${ }^{18} \mathrm{~F}-\mathrm{FMISO}$ may have a role in directing and monitoring targeted hypoxic therapy (110).

Another radiotracer, ${ }^{18} \mathrm{~F}$-fluorothymidine $\left({ }^{18} \mathrm{~F}-\mathrm{FLT}\right)$, is a thymidine analog developed for the purpose of imaging tumor cell proliferation (111). ${ }^{18}$ F-FLT has been used in diagnosis and assessment of glioma grading, in differentiating tumor recurrence from radionecrosis, in assessing response to treatment, and in predicting overall survival (112). In an image-guided biopsy study, results demonstrated that ${ }^{18} \mathrm{~F}$-FLT, while a useful marker of cell proliferation, and although correlated with regional variations in cell proliferation, was unable to identify the margin of gliomas (113). This is due to the fact that ${ }^{18} \mathrm{~F}$-FLT is not able to penetrate the intact blood-brain barrier and normally accumulates only in areas with contrast enhancement on MRI $(114,115)$.

${ }^{11} \mathrm{C}$-Choline has been used as a marker of cell membrane phospholipids in brain tumors, exhibiting a significant correlation of uptake with the degree of glioma malignancy (116). However, as is the case with ${ }^{18} \mathrm{~F}-\mathrm{FLT}$, tracer uptake is limited to areas with blood-brain barrier disruption and therefore this tracer offers limited additional information compared to a contrast-enhanced MRI. It should nevertheless be emphasized that, despite their many advantages, the majority of these radiotracers as well as multiple others are not widely available and are only used in a limited number of centers since they require wellexperienced staff with on-site radiochemistry equipment and cyclotron. These radiotracers are currently available only in research centers. Furthermore, future perspectives also include multimodality imaging. Accordingly, technological innovations in glioma imaging assessment such as simultaneous acquisition of anatomic and functional images with the integration of PET-MRI data appear to be of particular promise for research, diagnosis, and treatment of glioblastomas. Fully integrated PET/MRI scanners are now available and the number of scanner installations and published studies is steadily on the rise (117-119). Furthermore, hybrid PET-MRI systems offer improved patient comfort due to a significant reduction in measurement time and improved spatial and temporal co-recording of PET and MRI data. Hybrid PET-MR allows comparing amino acid PET data with advanced MR parameters including perfusion-weighted imaging, magnetic resonance spectroscopy, and diffusionweighted imaging (118).

In addition to this technical multimodality and the concomitant efforts of using various radiopharmaceuticals to characterize multiple biological targets $(61,105)$, currently used multiparametric imaging also integrates the development and applications of innovative methods of image processing and analysis (120). While common metrics such as standard uptake value (SUV) or BTV or TBR only partially describes the properties of pathological lesions, novel parameters such as shape and uptake heterogeneity may provide additional information on the biological profile associated with tumor aggressiveness or degree of response to specific treatment and, consequently, with prognosis (121). 


\section{Conclusion}

In summary, PET is a nuclear medicine imaging method with increasing relevance in diagnosis, therapy monitoring, and prognostication of glioblastomas. In clinical practice, currently used radiotracers are focused on imaging of glucose metabolism and amino acid transport. Both classes of tracers can provide information on grading and prognosis of gliomas, but amino acid tracers, which exhibit lower uptake in normal brain tissue, are better suited for delineation of tumor extent, treatment planning, and follow-up than ${ }^{18} \mathrm{~F}-\mathrm{FDG}$. Although the use of PET in the diagnosis of glioblastomas is still at an early stage of development in clinical practice, development of novel radiotracers and recent innovations in multimodality imaging are expected to enhance its use in the assessment of these tumors in the near future.

Acknowledgment: The authors thank Pierre Pothier for the editing this article.

Conflict of interest: The authors declare no potential conflicts of interest with respect to research, authorship, and/or publication of this article.

Copyright and permission statement: To the best of our knowledge, the materials included in this chapter do not violate copyright laws. All original sources have been appropriately acknowledged and/or referenced. Where relevant, appropriate permissions have been obtained from the original copyright holder(s).

\section{References}

1. Ferlay J, Shin H-R, Bray F, Forman D, Mathers C, Parkin DM. Estimates of worldwide burden of cancer in 2008: GLOBOCAN 2008. Int J Cancer. 2010 Dec;127(12):2893-917. http://dx.doi. org/10.1002/ijc.25516

2. Ostrom QT, Gittleman H, Farah P, Ondracek A, Chen Y, Wolinsky Y, et al. CBTRUS statistical report: Primary brain and central nervous system tumors diagnosed in the United States in 2006-2010. Neuro-Oncology. 2013 Nov;15(Suppl 2):iil-56. http://dx.doi.org/10.1093/neuonc/not151

3. Louis DN, Ohgaki H, Wiestler OD, Cavenee WK, Burger PC, Jouvet A, et al. The 2007 WHO classification of tumours of the central nervous system. Acta Neuropathol (Berl). 2007 Aug;114(2):97-109. http://dx.doi.org/10.1007/s00401-007-0243-4

4. Ahmed R, Oborski MJ, Hwang M, Lieberman FS, Mountz JM. Malignant gliomas: Current perspectives in diagnosis, treatment, and early response assessment using advanced quantitative imaging methods. Cancer Manage Res. 2014;6:149-70.

5. Stupp R, Mason WP, van den Bent MJ, Weller M, Fisher B, Taphoorn MJB, et al. Radiotherapy plus concomitant and adjuvant temozolomide for glioblastoma. N Engl J Med. 2005 Mar;352(10):987-96. http://dx.doi.org/10.1056/NEJMoa043330

6. Chinot OL, Wick W, Mason W, Henriksson R, Saran F, Nishikawa R, et al. Bevacizumab plus radiotherapy-temozolomide for newly diagnosed glioblastoma. N Engl J Med. 2014 Feb;370(8):709-22. http://dx.doi.org/10.1056/NEJMoal308345

7. Weller M, van den Bent M, Hopkins K, Tonn JC, Stupp R, Falini A, et al. EANO guideline for the diagnosis and treatment of anaplastic gliomas and glioblastoma. Lancet Oncol. 2014 Aug;15(9):e395-403. http://dx.doi.org/10.1016/S1470-2045(14)70011-7 
8. Chen W, Silverman DHS. Advances in evaluation of primary brain tumors. Semin Nucl Med. 2008 Jul;38(4):240-50. http://dx.doi.org/10.1053/j.semnuclmed.2008.02.005

9. Heiss W-D. [PET in gliomas. Overview of current studies]. Nukl Nucl Med. 2014 Aug;53(4):163-171. http://dx.doi.org/10.3413/Nukmed-0662-14-04

10. Dhermain F. Radiotherapy of high-grade gliomas: Current standards and new concepts, innovations in imaging and radiotherapy, and new therapeutic approaches. Chin J Cancer. 2014 Jan;33(1):16-24. http://dx.doi.org/10.5732/cjc.013.10217

11. Levivier M, Becerra A, De Witte O, Brotchi J, Goldman S. Radiation necrosis or recurrence. J Neurosurg. 1996 Jan;84(1):148-9.

12. Colavolpe C, Metellus P, Mancini J, Barrie M, Béquet-Boucard C, Figarella-Branger D, et al. Independent prognostic value of pre-treatment 18 -FDG-PET in high-grade gliomas. J Neurooncol. 2012 May;107(3):527-35. http://dx.doi.org/10.1007/s11060-011-0771-6

13. Demetriades AK, Almeida AC, Bhangoo RS, Barrington SF. Applications of positron emission tomography in neuro-oncology: A clinical approach. Surg J R Coll Surg Edinb Irel. 2014 Jun;12(3):148-57. http://dx.doi.org/10.1016/j.surge.2013.12.001

14. von Neubeck C, Seidlitz A, Kitzler HH, Beuthien-Baumann B, Krause M. Glioblastoma multiforme: Emerging treatments and stratification markers beyond new drugs. Br J Radiol. 2015 Sep;88(1053):20150354. http://dx.doi.org/10.1259/bjr.20150354

15. Grosu A-L, Weber WA, Riedel E, Jeremic B, Nieder C, Franz M, et al. L-(methyl-11C) methionine positron emission tomography for target delineation in resected high-grade gliomas before radiotherapy. Int J Radiat Oncol Biol Phys. 2005 Sep;63(1):64-74. http://dx.doi.org/10.1016/j. ijrobp.2005.01.045

16. Wang L, Lieberman BP, Ploessl K, Kung HF. Synthesis and evaluation of ${ }^{18} \mathrm{~F}$ labeled FET prodrugs for tumor imaging. Nucl Med Biol. 2014 Jan;4l(1):58-67. http://dx.doi.org/10.1016/j.nucmedbio. 2013.09.011

17. Janvier L, Olivier P, Blonski M, Morel O, Vignaud J-M, Karcher G, et al. Correlation of SUV-derived indices with tumoral aggressiveness of gliomas in static 18F-FDOPA PET: Use in clinical practice. Clin Nucl Med. 2015 Sep;40(9):e429-35. http://dx.doi.org/10.1097/RLU.0000000000000897

18. Kosaka N, Tsuchida T, Uematsu H, Kimura H, Okazawa H, Itoh H. 18F-FDG PET of common enhancing malignant brain tumors. AJR Am J Roentgenol. 2008 Jun;190(6):W365-9. http://dx.doi. org/10.2214/AJR.07.2660

19. De Witte O, Lefranc F, Levivier M, Salmon I, Brotchi J, Goldman S. FDG-PET as a prognostic factor in high-grade astrocytoma. J Neurooncol. 2000 Sep;49(2):157-63. http://dx.doi.org/10.1023/A: 1026518002800

20. Spence AM, Muzi M, Graham MM, O'Sullivan F, Link JM, Lewellen TK, et al. 2-[(18)F]Fluoro-2deoxyglucose and glucose uptake in malignant gliomas before and after radiotherapy: Correlation with outcome. Clin Cancer Res Off J Am Assoc Cancer Res. 2002 Apr;8(4):971-9.

21. Yamashita K, Yoshiura T, Hiwatashi A, Togao O, Yoshimoto K, Suzuki SO, et al. Differentiating primary CNS lymphoma from glioblastoma multiforme: Assessment using arterial spin labeling, diffusion-weighted imaging, and ${ }^{18} \mathrm{~F}$-fluorodeoxyglucose positron emission tomography. Neuroradiology. 2013 Feb;55(2):135-43. http://dx.doi.org/10.1007/s00234-012-1089-6

22. Omuro AM, Leite CC, Mokhtari K, Delattre J-Y. Pitfalls in the diagnosis of brain tumours. Lancet Neurol. 2006 Nov;5(11):937-48. http://dx.doi.org/10.1016/S1474-4422(06)70597-X

23. Chung J-K, Kim YK, Kim S, Lee YJ, Paek S, Yeo JS, et al. Usefulness of 11C-methionine PET in the evaluation of brain lesions that are hypo- or isometabolic on 18F-FDG PET. Eur J Nucl Med Mol Imaging. 2002 Feb;29(2):176-82. http://dx.doi.org/10.1007/s00259-001-0690-4

24. Chen W, Silverman DHS, Delaloye S, Czernin J, Kamdar N, Pope W, et al. 18F-FDOPA PET imaging of brain tumors: Comparison study with 18F-FDG PET and evaluation of diagnostic accuracy. J Nucl Med Off Publ Soc Nucl Med. 2006 Jun;47(6):904-11.

25. Plotkin M, Blechschmidt C, Auf G, Nyuyki F, Geworski L, Denecke T, et al. Comparison of F-18 FETPET with F-18 FDG-PET for biopsy planning of non-contrast-enhancing gliomas. Eur Radiol. 2010 Oct;20(10):2496-502. http://dx.doi.org/10.1007/s00330-010-1819-2

26. Grosu A-L, Astner ST, Riedel E, Nieder C, Wiedenmann N, Heinemann F, et al. An interindividual comparison of O-(2-[18F]fluoroethyl)-L-tyrosine (FET)- and L-[methyl-11C]methionine (MET)-PET 
in patients with brain gliomas and metastases. Int J Radiat Oncol Biol Phys. 2011 Nov;81(4):1049-58. http://dx.doi.org/10.1016/j.ijrobp.2010.07.002

27. Rapp M, Heinzel A, Galldiks N, Stoffels G, Felsberg J, Ewelt C, et al. Diagnostic performance of 18F-FET PET in newly diagnosed cerebral lesions suggestive of glioma. J Nucl Med. 2013 Feb;54(2):229-35

28. Hutterer M, Nowosielski M, Putzer D, Jansen NL, Seiz M, Schocke M, et al. [18F]-fluoro-ethyl-Ltyrosine PET: A valuable diagnostic tool in neuro-oncology, but not all that glitters is glioma. Neuro Oncol. 2013 Mar;15(3):341-51 http://dx.doi.org/10.1093/neuonc/nos300

29. Jansen NL, Suchorska B, Wenter V, Schmid-Tannwald C, Todica A, Eigenbrod S, et al. Prognostic significance of dynamic 18F-FET PET in newly diagnosed astrocytic high-grade glioma. J Nucl Med Off Publ Soc Nucl Med. 2015 Jan;56(1):9-15. http://dx.doi.org/10.2967/jnumed.114.144675

30. Spaeth N, Wyss MT, Weber B, Scheidegger S, Lutz A, Verwey J, et al. Uptake of 18F-fluorocholine, 18F-fluoroethyl-L-tyrosine, and 18F-FDG in acute cerebral radiation injury in the rat: Implications for separation of radiation necrosis from tumor recurrence. J Nucl Med Off Publ Soc Nucl Med. 2004 Nov;45(11):1931-8.

31. Floeth FW, Pauleit D, Sabel M, Reifenberger G, Stoffels G, Stummer W, et al. 18F-FET PET differentiation of ring-enhancing brain lesions. J Nucl Med Off Publ Soc Nucl Med. 2006 May;47(5): 776-82.

32. Sala Q, Metellus P, Taieb D, Kaphan E, Figarella-Branger D, Guedj E. 18F-DOPA, a clinically available PET tracer to study brain inflammation? Clin Nucl Med. 2014 Apr;39(4):e283-5. http://dx.doi. org/10.1097/RLU.0000000000000383

33. Becherer A, Karanikas G, Szabó M, Zettinig G, Asenbaum S, Marosi C, et al. Brain tumour imaging with PET: A comparison between [18F]fluorodopa and [11C]methionine. Eur J Nucl Med Mol Imaging. 2003 Nov;30(11):1561-7. http://dx.doi.org/10.1007/s00259-003-1259-1

34. Dunet V, Pomoni A, Hottinger A, Nicod-Lalonde M, Prior JO. Performance of 18F-FET versus 18F-FDG-PET for the diagnosis and grading of brain tumors: Systematic review and meta-analysis. Neuro-Oncology. 2016 Mar;18(3):426-34. http://dx.doi.org/10.1093/neuonc/novl48

35. Fueger BJ, Czernin J, Cloughesy T, Silverman DH, Geist CL, Walter MA, et al. Correlation of 6-18F-fluoro-L-dopa PET uptake with proliferation and tumor grade in newly diagnosed and recurrent gliomas. J Nucl Med Off Publ Soc Nucl Med. 2010 Oct;51(10):1532-8. http://dx.doi.org/10.2967/ jnumed.110.078592

36. Sato N, Suzuki M, Kuwata N, Kuroda K, Wada T, Beppu T, et al. Evaluation of the malignancy of glioma using 11C-methionine positron emission tomography and proliferating cell nuclear antigen staining. Neurosurg Rev. 1999 Dec;22(4):210-14. http://dx.doi.org/10.1007/s101430050018

37. Sadeghi N, Salmon I, Decaestecker C, Levivier M, Metens T, Wikler D, et al. Stereotactic comparison among cerebral blood volume, methionine uptake, and histopathology in brain glioma. AJNR Am J Neuroradiol. 2007 Mar;28(3):455-61.

38. Shinozaki N, Uchino Y, Yoshikawa K, Matsutani T, Hasegawa A, Saeki N, et al. Discrimination between low-grade oligodendrogliomas and diffuse astrocytoma with the aid of 11C-methionine positron emission tomography. J Neurosurg. 2011 Jun;114(6):1640-7. http://dx.doi.org/10.3171/2010.11. JNS10553

39. Ceyssens S, Van Laere K, de Groot T, Goffin J, Bormans G, Mortelmans L. [11C]methionine PET, histopathology, and survival in primary brain tumors and recurrence. AJNR Am J Neuroradiol. 2006 Aug;27(7):1432-7.

40. Yamamoto A, Hosoya T, Takahashi N, Iwahara S, Munakata K. Quantification of left ventricular regional functions using ECG-gated myocardial perfusion SPECT—Validation of left ventricular systolic functions-. Ann Nucl Med. 2006 Aug;20(7):449-56. http://dx.doi.org/10.1007/ BF02987253

41. Pöpperl G, Kreth FW, Mehrkens JH, Herms J, Seelos K, Koch W, et al. FET PET for the evaluation of untreated gliomas: Correlation of FET uptake and uptake kinetics with tumour grading. Eur J Nucl Med Mol Imaging. 2007 Dec;34(12):1933-42. http://dx.doi.org/10.1007/s00259-007-0534-y

42. Lohmann P, Herzog H, Rota Kops E, Stoffels G, Judov N, Filss C, et al. Dual-time-point O-(2-[(18)F] fluoroethyl)-L-tyrosine PET for grading of cerebral gliomas. Eur Radiol. 2015 Oct;25(10):3017-24. http://dx.doi.org/10.1007/s00330-015-3691-6 
43. Dunet V, Maeder P, Nicod-Lalonde M, Lhermitte B, Pollo C, Bloch J, et al. Combination of MRI and dynamic FET PET for initial glioma grading. Nukl Nucl Med. 2014 Aug;53(4):155-61. http://dx.doi. org/10.3413/Nukmed-0650-14-03

44. Moulin-Romsée G, D'Hondt E, de Groot T, Goffin J, Sciot R, Mortelmans L, et al. Non-invasive grading of brain tumours using dynamic amino acid PET imaging: Does it work for 11C-methionine? Eur J Nucl Med Mol Imaging. 2007 Dec;34(12):2082-7. http://dx.doi.org/10.1007/s00259-007-0557-4

45. Kratochwil C, Combs SE, Leotta K, Afshar-Oromieh A, Rieken S, Debus J, et al. Intra-individual comparison of ${ }^{18} \mathrm{~F}$-FET and ${ }^{18} \mathrm{~F}$-DOPA in PET imaging of recurrent brain tumors. Neuro-Oncology. 2014 Mar;16(3):434-40. http://dx.doi.org/10.1093/neuonc/not199

46. Schiepers C, Chen W, Cloughesy T, Dahlbom M, Huang S-C. 18F-FDOPA kinetics in brain tumors. J Nucl Med Off Publ Soc Nucl Med. 2007 Oct;48(10):1651-61. http://dx.doi.org/10.2967/ jnumed.106.039321

47. Wee CW, Sung W, Kang H-C, Cho KH, Han TJ, Jeong B-K, et al. Evaluation of variability in target volume delineation for newly diagnosed glioblastoma: A multi-institutional study from the Korean Radiation Oncology Group. Radiat Oncol Lond Engl. 2015 Jul;10:137. http://dx.doi.org/10.1186/ s13014-015-0439-z

48. Johnson PC, Hunt SJ, Drayer BP. Human cerebral gliomas: Correlation of postmortem MR imaging and neuropathologic findings. Radiology. 1989 Jan;170(1 Pt 1):211-17. http://dx.doi.org/10.1148/ radiology. 170.1.2535765

49. Watanabe M, Tanaka R, Takeda N. Magnetic resonance imaging and histopathology of cerebral gliomas. Neuroradiology. 1992;34(6):463-9. http://dx.doi.org/10.1007/BF00598951

50. Galldiks N, Ullrich R, Schroeter M, Fink GR, Jacobs AH, Kracht LW. Volumetry of [(11)C]-methionine PET uptake and MRI contrast enhancement in patients with recurrent glioblastoma multiforme. Eur J Nucl Med Mol Imaging. 2010 Jan;37(1):84-92. http://dx.doi.org/10.1007/s00259-009-1219-5

51. Pauleit D, Floeth F, Hamacher K, Riemenschneider MJ, Reifenberger G, Müller H-W, et al. O-(2-[18F]fluoroethyl)-L-tyrosine PET combined with MRI improves the diagnostic assessment of cerebral gliomas. Brain J Neurol. 2005 Mar;128(Pt 3):678-87. http://dx.doi.org/10.1093/ brain/awh399

52. Lopez WOC, Cordeiro JG, Albicker U, Doostkam S, Nikkhah G, Kirch RD, et al. Correlation of (18) F-fluoroethyl tyrosine positron-emission tomography uptake values and histomorphological findings by stereotactic serial biopsy in newly diagnosed brain tumors using a refined software tool. OncoTargets Ther. 2015;8:3803-15. http://dx.doi.org/10.2147/OTT.S87126

53. Filss CP, Galldiks N, Stoffels G, Sabel M, Wittsack HJ, Turowski B, et al. Comparison of 18F-FET PET and perfusion-weighted MR imaging: A PET/MR imaging hybrid study in patients with brain tumors. J Nucl Med Off Publ Soc Nucl Med. 2014 Apr;55(4):540-5. http://dx.doi.org/10.2967/ jnumed.113.129007

54. Buchmann N, Kläsner B, Gempt J, Bauer JS, Pyka T, Delbridge C, et al. (18)F-Fluoroethyl-1thyrosine positron emission tomography to delineate tumor residuals after glioblastoma resection: A comparison with standard postoperative magnetic resonance imaging. World Neurosurg. 2016 May;89:420-6. http://dx.doi.org/10.1016/j.wneu.2016.02.032

55. Cicone F, Filss CP, Minniti G, Rossi-Espagnet C, Papa A, Scaringi C, et al. Volumetric assessment of recurrent or progressive gliomas: Comparison between F-DOPA PET and perfusion-weighted MRI. Eur J Nucl Med Mol Imaging. 2015 May;42(6):905-15. http://dx.doi.org/10.1007/ s00259-015-3018-5

56. Pafundi DH, Laack NN, Youland RS, Parney IF, Lowe VJ, Giannini C, et al. Biopsy validation of 18F-DOPA PET and biodistribution in gliomas for neurosurgical planning and radiotherapy target delineation: Results of a prospective pilot study. Neuro-Oncology. 2013 Aug;15(8):1058-67. http:// dx.doi.org/10.1093/neuonc/not002

57. Ledezma CJ, Chen W, Sai V, Freitas B, Cloughesy T, Czernin J, et al. 18F-FDOPA PET/MRI fusion in patients with primary/recurrent gliomas: Initial experience. Eur J Radiol. 2009 Aug;71(2):242-8. http://dx.doi.org/10.1016/j.ejrad.2008.04.018

58. Lindberg OR, McKinney A, Engler JR, Koshkakaryan G, Gong H, Robinson AE, et al. GBM heterogeneity as a function of variable epidermal growth factor receptor variant III activity. Oncotarget. 2016 Nov 29;7(48):79101-79116. http://dx.doi.org/10.18632/oncotarget.12600 
59. Pirotte B, Goldman S, Brucher JM, Zomosa G, Baleriaux D, Brotchi J, et al. PET in stereotactic conditions increases the diagnostic yield of brain biopsy. Stereotact Funct Neurosurg. 1994;63(1-4):144-9.

60. Pirotte B, Goldman S, Massager N, David P, Wikler D, Vandesteene A, et al. Comparison of 18F-FDG and 11C-methionine for PET-guided stereotactic brain biopsy of gliomas. J Nucl Med Off Publ Soc Nucl Med. 2004 Aug;45(8):1293-8.

61. Pirotte BJM, Levivier M, Goldman S, Massager N, Wikler D, Dewitte O, et al. Positron emission tomography-guided volumetric resection of supratentorial high-grade gliomas: A survival analysis in 66 consecutive patients. Neurosurgery. 2009 Mar;64(3):471-481. http://dx.doi.org/10.1227/01. NEU.0000338949.94496.85

62. Suchorska B, Jansen NL, Linn J, Kretzschmar H, Janssen H, Eigenbrod S, et al. Biological tumor volume in 18FET-PET before radiochemotherapy correlates with survival in GBM. Neurology. 2015 Feb;84(7):710-19. http://dx.doi.org/10.1212/WNL.0000000000001262

63. Tralins KS, Douglas JG, Stelzer KJ, Mankoff DA, Silbergeld DL, Rostomily RC, et al. Volumetric analysis of 18F-FDG PET in glioblastoma multiforme: Prognostic information and possible role in definition of target volumes in radiation dose escalation. J Nucl Med Off Publ Soc Nucl Med. 2002 Dec;43(12):1667-73.

64. Kosztyla R, Chan EK, Hsu F, Wilson D, Ma R, Cheung A, et al. High-grade glioma radiation therapy target volumes and patterns of failure obtained from magnetic resonance imaging and 18F-FDOPA positron emission tomography delineations from multiple observers. Int J Radiat Oncol Biol Phys. 2013 Dec;87(5):1100-6. http://dx.doi.org/10.1016/j.ijrobp.2013.09.008

65. Navarria P, Reggiori G, Pessina F, Ascolese AM, Tomatis S, Mancosu P, et al. Investigation on the role of integrated PET/MRI for target volume definition and radiotherapy planning in patients with high grade glioma. Radiother Oncol J Eur Soc Ther Radiol Oncol. 2014 Sep;112(3):425-9. http://dx.doi. org/10.1016/j.radonc.2014.09.004

66. Lee IH, Piert M, Gomez-Hassan D, Junck L, Rogers L, Hayman J, et al. Association of 11C-methionine PET uptake with site of failure after concurrent temozolomide and radiation for primary glioblastoma multiforme. Int J Radiat Oncol Biol Phys. 2009 Feb;73(2):479-85. http://dx.doi.org/10.1016/j. ijrobp.2008.04.050

67. Grosu AL, Weber WA, Franz M, Stärk S, Piert M, Thamm R, et al. Reirradiation of recurrent highgrade gliomas using amino acid PET (SPECT)/CT/MRI image fusion to determine gross tumor volume for stereotactic fractionated radiotherapy. Int J Radiat Oncol Biol Phys. 2005 Oct;63(2):511-19. http://dx.doi.org/10.1016/j.ijrobp.2005.01.056

68. Poulsen SH, Urup T, Grunnet K, Christensen IJ, Larsen VA, Jensen ML, et al. The prognostic value of FET PET at radiotherapy planning in newly diagnosed glioblastoma. Eur J Nucl Med Mol Imaging. 2017 Mar;44(3):373-381.

69. Lundemann M, Costa JC, Law I, Engelholm SA, Muhic A, Poulsen HS, et al. Patterns of failure for patients with glioblastoma following O-(2-[(18)F]fluoroethyl)-L-tyrosine PET- and MRI-guided radiotherapy. Radiother Oncol. 2017 Mar;122(3):380-386.

70. Rickhey M, Koelbl O, Eilles C, Bogner L. A biologically adapted dose-escalation approach, demonstrated for 18F-FET-PET in brain tumors. Strahlenther Onkol Organ Dtsch Rontgengesellschaft Al. 2008 Oct;184(10):536-42. http://dx.doi.org/10.1007/s00066-008-1883-6

71. Weber DC, Zilli T, Buchegger F, Casanova N, Haller G, Rouzaud M, et al. [(18)F]Fluoroethyltyrosinepositron emission tomography-guided radiotherapy for high-grade glioma. Radiat Oncol Lond Engl. 2008 Dec ;3:44. http://dx.doi.org/10.1186/1748-717X-3-44

72. Miwa K, Matsuo M, Ogawa S, Shinoda J, Yokoyama K, Yamada J, et al. Re-irradiation of recurrent glioblastoma multiforme using 11C-methionine PET/CT/MRI image fusion for hypofractionated stereotactic radiotherapy by intensity modulated radiation therapy. Radiat Oncol Lond Engl. 2014;9:181. http://dx.doi.org/10.1186/1748-717X-9-181

73. Macdonald DR, Cascino TL, Schold SC, Cairncross JG. Response criteria for phase II studies of supratentorial malignant glioma. J Clin Oncol Off J Am Soc Clin Oncol. 1990 Jul;8(7):1277-80. http:// dx.doi.org/10.1200/JCO.1990.8.7.1277

74. Brandsma D, Stalpers L, Taal W, Sminia P, van den Bent MJ. Clinical features, mechanisms, and management of pseudoprogression in malignant gliomas. Lancet Oncol. 2008 May;9(5):453-61. http:// dx.doi.org/10.1016/S1470-2045(08)70125-6 
75. Wen PY, Macdonald DR, Reardon DA, Cloughesy TF, Sorensen AG, Galanis E, et al. Updated response assessment criteria for high-grade gliomas: Response assessment in Neuro-Oncology Working Group. J Clin Oncol. 2010 Apr;28(11):1963-72. http://dx.doi.org/10.1200/JCO.2009.26.3541

76. Shah AH, Snelling B, Bregy A, Patel PR, Tememe D, Bhatia R, et al. Discriminating radiation necrosis from tumor progression in gliomas: A systematic review what is the best imaging modality? J Neurooncol. 2013 Apr;112(2):141-52. http://dx.doi.org/10.1007/s11060-013-1059-9

77. Brandsma D, van den Bent MJ. Pseudoprogression and pseudoresponse in the treatment of gliomas. Curr Opin Neurol. 2009 Dec;22(6):633-8. http://dx.doi.org/10.1097/WCO.0b013e328332363e

78. Rozental JM, Levine RL, Mehta MP, Kinsella TJ, Levin AB, Algan O, et al. Early changes in tumor metabolism after treatment: The effects of stereotactic radiotherapy. Int J Radiat Oncol Biol Phys. 1991 May;20(5):1053-60. http://dx.doi.org/10.1016/0360-3016(91)90204-H

79. Charnley N, West CM, Barnett CM, Brock C, Bydder GM, Glaser M, et al. Early change in glucose metabolic rate measured using FDG-PET in patients with high-grade glioma predicts response to temozolomide but not temozolomide plus radiotherapy. Int J Radiat Oncol Biol Phys. 2006 Oct;66(2):331-8. http://dx.doi.org/10.1016/j.ijrobp.2006.04.043

80. Nihashi T, Dahabreh IJ, Terasawa T. Diagnostic accuracy of PET for recurrent glioma diagnosis: A meta-analysis. AJNR Am J Neuroradiol. 2013 May;34(5):944-50, S1-11.

81. Chao ST, Suh JH, Raja S, Lee SY, Barnett G. The sensitivity and specificity of FDG PET in distinguishing recurrent brain tumor from radionecrosis in patients treated with stereotactic radiosurgery. Int J Cancer. 2001 Jun 20;96(3):191-7. http://dx.doi.org/10.1002/ijc.1016

82. Galldiks N, Langen K-J. Amino acid PET_An imaging option to identify treatment response, posttherapeutic effects, and tumor recurrence? Front Neurol. 2016;7:120. http://dx.doi.org/10.3389/ fneur.2016.00120

83. Van Laere K, Ceyssens S, Van Calenbergh F, de Groot T, Menten J, Flamen P, et al. Direct comparison of 18F-FDG and 11C-methionine PET in suspected recurrence of glioma: Sensitivity, inter-observer variability and prognostic value. Eur J Nucl Med Mol Imaging. 2005 Jan;32(1):39-51. http://dx.doi. org/10.1007/s00259-004-1564-3

84. Galldiks N, Kracht LW, Burghaus L, Thomas A, Jacobs AH, Heiss W-D, et al. Use of 11C-methionine PET to monitor the effects of temozolomide chemotherapy in malignant gliomas. Eur J Nucl Med Mol Imaging. 2006 May;33(5):516-24. http://dx.doi.org/10.1007/s00259-005-0002-5

85. Beppu T, Terasaki K, Sasaki T, Sato Y, Tomabechi M, Kato K, et al. MRI and 11C-methyl-L-methionine PET Differentiate Bevacizumab True Responders After Initiating Therapy for Recurrent Glioblastoma. Clin Nucl Med. 2016 Nov;4l(11):852-7. http://dx.doi.org/10.1097/RLU.0000000000001377

86. Galldiks N, Langen K-J, Holy R, Pinkawa M, Stoffels G, Nolte KW, et al. Assessment of treatment response in patients with glioblastoma using $\mathrm{O}-(2-18 \mathrm{~F}-$ fluoroethyl)-L-tyrosine PET in comparison to MRI. J Nucl Med. 2012 Jul;53(7):1048-57. http://dx.doi.org/10.2967/jnumed.111.098590

87. Galldiks N, Dunkl V, Stoffels G, Hutterer M, Rapp M, Sabel M, et al. Diagnosis of pseudoprogression in patients with glioblastoma using O-(2-[18F]fluoroethyl)-L-tyrosine PET. Eur J Nucl Med Mol Imaging. 2015 Apr;42(5):685-95. http://dx.doi.org/10.1007/s00259-014-2959-4

88. Kebir S, Khurshid Z, Gaertner FC, Essler M, Hattingen E, Fimmers R, et al. Unsupervised consensus cluster analysis of [18F]-fluoroethyl-L-tyrosine positron emission tomography identified textural features for the diagnosis of pseudoprogression in high-grade glioma. Oncotarget. 2017 Jan 31;8(5):8294-8304.

89. Kebir S, Fimmers R, Galldiks N, Schäfer N, Mack F, Schaub C, et al. Late pseudoprogression in glioblastoma: Diagnostic value of dynamic O-(2-[18F]fluoroethyl)-L-tyrosine PET. Clin Cancer Res Off J Am Assoc Cancer Res. 2016 May;22(9):2190-6. http://dx.doi.org/10.1158/1078-0432. CCR-15-1334

90. Schwarzenberg J, Czernin J, Cloughesy TF, Ellingson BM, Pope WB, Grogan T, et al. Treatment response evaluation using 18F-FDOPA PET in patients with recurrent malignant glioma on bevacizumab therapy. Clin Cancer Res Off J Am Assoc Cancer Res. 2014 Jul;20(13):3550-9. http://dx.doi. org/10.1158/1078-0432.CCR-13-1440

91. Harris RJ, Cloughesy TF, Pope WB, Nghiemphu PL, Lai A, Zaw T, et al. 18F-FDOPA and 18F-FLT positron emission tomography parametric response maps predict response in recurrent malignant 
gliomas treated with bevacizumab. Neuro-Oncology. 2012 Aug;14(8):1079-89. http://dx.doi. org/10.1093/neuonc/nosl41

92. Hutterer M, Nowosielski M, Putzer D, Waitz D, Tinkhauser G, Kostron H, et al. O-(2-18F-fluoroethyl)L-tyrosine PET predicts failure of antiangiogenic treatment in patients with recurrent high-grade glioma. J Nucl Med Off Publ Soc Nucl Med. 2011 Jun;52(6):856-64. http://dx.doi.org/10.2967/ jnumed.110.086645

93. Galldiks N, Rapp M, Stoffels G, Dunkl V, Sabel M, Langen K-J. Earlier diagnosis of progressive disease during bevacizumab treatment using O-(2-18F-fluorethyl)-L-tyrosine positron emission tomography in comparison with magnetic resonance imaging. Mol Imaging. 2013 Aug;12(5):273-6.

94. Galldiks N, Rapp M, Stoffels G, Fink GR, Shah NJ, Coenen HH, et al. Response assessment of bevacizumab in patients with recurrent malignant glioma using [18F]Fluoroethyl-L-tyrosine PET in comparison to MRI. Eur J Nucl Med Mol Imaging. 2013 Jan;40(1):22-33. http://dx.doi.org/10.1007/ s00259-012-2251-4

95. Takenaka S, Asano Y, Shinoda J, Nomura Y, Yonezawa S, Miwa K, et al. Comparison of (11) C-methionine, (11)C-choline, and (18)F-fluorodeoxyglucose-PET for distinguishing glioma recurrence from radiation necrosis. Neurol Med Chir (Tokyo). 2014;54(4):280-9. http://dx.doi. org/10.2176/nmc.oa2013-0117

96. Karunanithi S, Sharma P, Kumar A, Khangembam BC, Bandopadhyaya GP, Kumar R, et al. 18F-FDOPA PET/CT for detection of recurrence in patients with glioma: Prospective comparison with 18F-FDG PET/CT. Eur J Nucl Med Mol Imaging. 2013 Jul;40(7):1025-35. http://dx.doi.org/10.1007/ s00259-013-2384-0

97. Herrmann K, Czernin J, Cloughesy T, Lai A, Pomykala KL, Benz MR, et al. Comparison of visual and semiquantitative analysis of 18F-FDOPA-PET/CT for recurrence detection in glioblastoma patients. Neuro-Oncology. 2014 Apr;16(4):603-9. http://dx.doi.org/10.1093/neuonc/not166

98. Galldiks N, Stoffels G, Filss C, Rapp M, Blau T, Tscherpel C, et al. The use of dynamic O-(2-18Ffluoroethyl)-l-tyrosine PET in the diagnosis of patients with progressive and recurrent glioma. NeuroOncology. 2015 Sep;17(9):1293-300. http://dx.doi.org/10.1093/neuonc/nov088

99. Pöpperl G, Götz C, Rachinger W, Gildehaus F-J, Tonn J-C, Tatsch K. Value of O-(2-[18F]fluoroethyl)L-tyrosine PET for the diagnosis of recurrent glioma. Eur J Nucl Med Mol Imaging. 2004 Nov;31(11):1464-70. http://dx.doi.org/10.1007/s00259-004-1590-1

100. Chiang GC, Galla N, Ferraro R, Kovanlikaya I. The added prognostic value of metabolic tumor size on FDG-PET at first suspected recurrence of glioblastoma multiforme: FDG-PET for prognosis of recurrent glioblastoma. J Neuroimaging. 2017 Mar;27(2):243-247. http://dx.doi.org/10.1111/jon. 12386

101. Colavolpe C, Chinot O, Metellus P, Mancini J, Barrie M, Bequet-Boucard C, et al. FDG-PET predicts survival in recurrent high-grade gliomas treated with bevacizumab and irinotecan. Neuro-Oncology. 2012 May;14(5):649-57. http://dx.doi.org/10.1093/neuonc/nos012

102. Lopci E, Riva M, Olivari L, Raneri F, Soffietti R, Piccardo A, et al. Prognostic value of molecular and imaging biomarkers in patients with supratentorial glioma. Eur J Nucl Med Mol Imaging. 2017 Jul;44(7):1155-1164. http://dx.doi.org/10.1007/s00259-017-3618-3

103. Galldiks N, Dunkl V, Kracht LW, Vollmar S, Jacobs AH, Fink GR, et al. Volumetry of [11C]-methionine positron emission tomographic uptake as a prognostic marker before treatment of patients with malignant glioma. Mol Imaging. 2012 Dec;11(6):516-27.

104. Karunanithi S, Sharma P, Kumar A, Gupta DK, Khangembam BC, Ballal S, et al. Can (18)F-FDOPA PET/CT predict survival in patients with suspected recurrent glioma? A prospective study. Eur J Radiol. 2014 Jan;83(1):219-25. http://dx.doi.org/10.1016/j.ejrad.2013.09.004

105. Toyonaga T, Yamaguchi S, Hirata K, Kobayashi K, Manabe O, Watanabe S, et al. Hypoxic glucose metabolism in glioblastoma as a potential prognostic factor. Eur J Nucl Med Mol Imaging. 2016 Oct 18; http://dx.doi.org/10.1007/s11060-016-2077-1

106. Frosina G. Positron emission tomography of high-grade gliomas. J Neurooncol. 2016 May;127(3): $415-25$.

107. Rasey JS, Koh W, Evans ML, Peterson LM, Lewellen TK, Graham MM, et al. Quantifying regional hypoxia in human tumors with positron emission tomography of [18F]fluoromisonidazole: A pretherapy study of 37 patients. Int J Radiat Oncol. 1996 Sep;36(2):417-28. http://dx.doi.org/10.1016/S0360-3016(96)00325-2 
108. Whitmore GF, Varghese AJ. The biological properties of reduced nitroheterocyclics and possible underlying biochemical mechanisms. Biochem Pharmacol. 1986 Jan;35(1):97-103. http://dx.doi. org/10.1016/0006-2952(86)90565-4

109. Brown JM. Therapeutic targets in radiotherapy. Int J Radiat Oncol. 2001 Feb;49(2):319-26. http:// dx.doi.org/10.1016/S0360-3016(00)01482-6

110. Cher LM, Murone C, Lawrentschuk N, Ramdave S, Papenfuss A, Hannah A, et al. Correlation of hypoxic cell fraction and angiogenesis with glucose metabolic rate in gliomas using 18F-fluoromisonidazole, 18F-FDG PET, and immunohistochemical studies. J Nucl Med Off Publ Soc Nucl Med. 2006 Mar;47(3):410-18.

111. Shields AF, Grierson JR, Dohmen BM, Machulla H-J, Stayanoff JC, Lawhorn-Crews JM, et al. Imaging proliferation in vivo with [F-18]FLT and positron emission tomography. Nat Med. 1998 Nov;4(11):1334-6. http://dx.doi.org/10.1038/3337

112. Zhao F, Cui Y, Li M, Fu Z, Chen Z, Kong L, et al. Prognostic value of 3'-deoxy-3'-18F-fluorothymidine ([(18)F] FLT PET) in patients with recurrent malignant gliomas. Nucl Med Biol. 2014 Sep;41(8): 710-15. http://dx.doi.org/10.1016/j.nucmedbio.2014.04.134

113. Hart MG, Ypma RJF, Romero-Garcia R, Price SJ, Suckling J. Graph theory analysis of complex brain networks: New concepts in brain mapping applied to neurosurgery. J Neurosurg. 2016 Jun;124(6):1665-78. http://dx.doi.org/10.3171/2015.4.JNS142683

114. Chen W, Cloughesy T, Kamdar N, Satyamurthy N, Bergsneider M, Liau L, et al. Imaging proliferation in brain tumors with 18F-FLT PET: Comparison with 18F-FDG. J Nucl Med Off Publ Soc Nucl Med. 2005 Jun;46(6):945-52.

115. Jacobs AH, Thomas A, Kracht LW, Li H, Dittmar C, Garlip G, et al. 18F-fluoro-L-thymidine and 11C-methylmethionine as markers of increased transport and proliferation in brain tumors. J Nucl Med Off Publ Soc Nucl Med. 2005 Dec;46(12):1948-58.

116. Ohtani T, Kurihara H, Ishiuchi S, Saito N, Oriuchi N, Inoue T, et al. Brain tumour imaging with carbon-11 choline: Comparison with FDG PET and gadolinium-enhanced MR imaging. Eur J Nucl Med. 2001 Nov;28(11):1664-70. http://dx.doi.org/10.1007/s002590100620

117. Shah NJ, Oros-Peusquens A-M, Arrubla J, Zhang K, Warbrick T, Mauler J, et al. Advances in multimodal neuroimaging: Hybrid MR-PET and MR-PET-EEG at 3 T and 9.4 T. J Magn Reson San Diego Calif. 1997. 2013 Apr;229:101-15.

118. Neuner I, Kaffanke JB, Langen K-J, Kops ER, Tellmann L, Stoffels G, et al. Multimodal imaging utilising integrated MR-PET for human brain tumour assessment. Eur Radiol. 2012 Dec;22(12):2568-80. http://dx.doi.org/10.1007/s00330-012-2543-x

119. Deuschl C, Moenninghoff C, Goericke S, Kirchner J, Köppen S, Binse I, et al. Response assessment of bevacizumab therapy in GBM with integrated 11C-MET-PET/MRI: A feasibility study. Eur J Nucl Med Mol Imaging. 2017 Mar 3; http://dx.doi.org/10.1007/s00259-017-3661-0

120. Guedj E, Cammilleri S, Verger A. Predictive medicine: towards a multi-parametric imaging for a personal risk stratification. Eur J Nucl Med Mol Imaging. 2016 Sep 27;44(2):196-198.

121. Visvikis D, Hatt M, Tixier F, Cheze Le Rest C. The age of reason for FDG PET image-derived indices. Eur J Nucl Med Mol Imaging. 2012 Nov;39(11):1670-2. http://dx.doi.org/10.1007/ s00259-012-2239-0 